\title{
The effect of antimicrobial activity of Teucrium Polium on Oral Streptococcus Mutans: a randomized cross-over clinical trial study
}

Somayeh Khoramian Tusi ${ }^{1}$, Ahmad Jafari ${ }^{2,3^{*}}$ (D), Seyed Mahmoud Amin Marashi ${ }^{4}$, Salomeh Faramarzi Niknam ${ }^{1}$, Malihe Farid ${ }^{5}$ and Mehdi Ansari ${ }^{6}$

\begin{abstract}
Background: The purpose of this study is to determine the effect of a mouthwash containing Teucriumpolium herb on Streptococcus mutans in mouth.

Methods: This study was a randomized, crossover, double-blind clinical trial, where we selected 22 volunteers (dental students) randomly and we divided them into two groups. The study had two phases. In each phase, one group acted as the intervention group, while the other one was the control group. Both the intervention and control groups were given the mouthwash with and without Teucriumpolium, respectively. S. mutans of saliva were measured before and after each phase to compare the effects of the mouthwashes. A three-week washout period was considered between the two phases. An independent two-sample t-test was utilized to compare the mean of S. mutans colonies. Additionally, we used a standard AB/BA crossover model to find the results of the treatment and the impact of carryover on the residual's biological effects. The significance level was considered 0.05 in this experiment.
\end{abstract}

Results: There is no significant difference observed between the two groups in the number of S. mutans before using the mouthwashes. When the mouthwash containing Teucriumpolium was used, there was a significant decrease in the number of $S$. mutans colonies in both phases' extract $(P=0.002)$. Conclusion: The results of this study indicate the mouthwash containing aqueous extract of Teucrium polium can majorly reduce the colonization of $S$. mutans in human saliva.

Trial registration: Ethical issues approved by the Ethics Committee of the Rafsanjan University of Medical Sciences with the approval number of 937/9/31, IRCT code Number of IRCT2013121815842N1 and it was approved on 06/ 16/2014. The study was conducted in the period of September to November 2014.

Keywords: Mouthwash, Medicinal plants, Salvia, Herbal extract, Dental caries, Oral hygiene

\footnotetext{
* Correspondence: ajafari@tums.ac.ir

${ }^{2}$ Research Center for Caries Prevention, Dental Research Institute,

Department of Community Oral Health, School of Dentistry, Tehran

University of Medical Sciences, Tehran, Iran

${ }^{3}$ Department of Pediatric Dentistry, School of Dentistry, Al Hussain University,

Karbala, Iraq

Full list of author information is available at the end of the article
}

(c) The Author(s). 2020 Open Access This article is licensed under a Creative Commons Attribution 4.0 International License, which permits use, sharing, adaptation, distribution and reproduction in any medium or format, as long as you give appropriate credit to the original author(s) and the source, provide a link to the Creative Commons licence, and indicate if changes were made. The images or other third party material in this article are included in the article's Creative Commons licence, unless indicated otherwise in a credit line to the material. If material is not included in the article's Creative Commons licence and your intended use is not permitted by statutory regulation or exceeds the permitted use, you will need to obtain permission directly from the copyright holder. To view a copy of this licence, visit http://creativecommons.org/licenses/by/4.0/. The Creative Commons Public Domain Dedication waiver (http://creativecommons.org/publicdomain/zero/1.0/) applies to the data made available in this article, unless otherwise stated in a credit line to the data. 


\section{Background}

A healthy mouth is the gate to a healthy body. The effects of oral health on many systemic diseases and cancers are extensively studied and there are some proven theories [1-3]. Amongst a wide variety of microorganisms, Streptococcus pathogens, such as Streptococcus mutans (S. mutans), are worth mentioning. They can result dental caries, while they can also deteriorate the general health and oral hygiene of a human being. Ultimately, these bacteria can impose huge medical expenses or bring about teeth loss. Therefore, finding the substances that have the capability to remove or to minimize these microbial species is of high importance in respect to this subject. In recent years, herbal medicines are receiving a great attention (based on the knowledge of traditional medicine) to prevent and to treat various illnesses. Dental science keeps up with the other medical specialties to utilize herbal and traditional medicine in the realm of oral health too. Some studies investigate the effect of medicinal plants as antibacterial agents in dentistry $[4,5]$, while herbal extracts are widely used in oral hygiene products as well. In some studies on mouthwashes, chlorhexidine is used as a positive control to compare the efficacy of other products, and is believed to be superior to other chemical ingredients such as listerine and betadine [6]. However, the incidence of such side effects as undesirable tooth discoloration, unpleasant taste, dryness, and burning sensation in the mouth might discourage patients to use mouthwashes containing this ingredient [7]. To overcome such side effects, nontoxic herbal mouthwashes using various herbs and plant extracts have been introduced.

Polei-gamander, with the scientific name of Teucriumpolium (T. polium), is a kind of peppermint that is a component of aromatic plants. It contains some organic materials with antibacterial effects [8]. T. polium or Polei-gamander is one of the medicinal herbs in traditional medicine, which has been used cancer treatments [8], gastrointestinal disorders [9], kidney and kidney stones [10], wound healing [11], and diabetes [12].

In dentistry, T. polium is consumed to produce probiotic compounds containing herbal extracts [13]. Antimicrobial mouthwashes work in a variety of ways, including the connection to the bacterial cell wall and the destruction of the wall. However, there is an immediate need to conduct extensive researches in this realm. Such studies will assist us in understanding the mechanism of such antibacterial activities as well as a better perspective of $T$. polium's effect on $S$. mutans. As a result, the purpose of the current research is to investigate the effect of a mouthwash containing $T$. polium herb on the number of salivary Streptococcus mutans.

\section{Methods}

An AB/BA randomized, crossover, double-blind clinical trial study was designed (Fig. 1).The Ethics Committee of

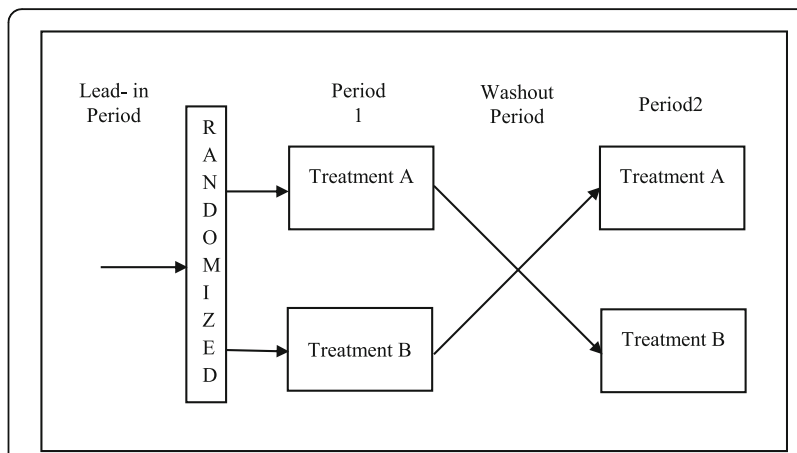

Treatment A: Using T. polium mouthwash

Treatment B: Using the placebo mouthwash

Fig. 1 AB/BA randomized, crossover study design. Treatment A: Using T. polium mouthwash. Treatment B: Using the placebo mouthwash

the Rafsanjan University of Medical Sciences approved the ethical issues. The approval number is 937/9/31 and with the reference code of IRCT2013121815842N1 from the Iranian Registry of Clinical Trials (IRCT).

\section{Inclusion criteria}

Inclusion included four criteria: Not using antibiotics in the last month, Not having active caries, Plaque index equal to or less than 20\% (demographics aging from eighteen to twenty-five years old) and signing a consent form before participating in this study.

\section{Samples}

Samples were selected from dental students of Rafsanjan School of Dentistry. Sample size was calculated based on a previous study [14]. The following formula was used to estimate the sample size:

$$
\begin{aligned}
& n_{1}=n_{2}=\frac{\sigma_{d}^{2}\left(Z_{1 \frac{a}{2}}+Z_{1-\beta}\right)^{2}}{2 \Delta^{2}} \\
& \quad\left(\alpha=0.05 \rightarrow Z_{1 \frac{a}{2}}=1.96 ; \beta=0.10 \rightarrow Z_{1-\beta}=1.29 ; \sigma_{d}=5.61 ; \Delta=4\right)
\end{aligned}
$$

Therefore: $n_{1}=n_{2} \approx 11$. As a result, each group needed eleven samples.

Twenty-two dental students, who volunteered to participate, were randomly chosen and were put into two categories: Intervention group and control group. Each group included 11 individuals of both genders.

Number 1 (representing the intervention group) and number 2 (representing the control group) were written on twenty-two pieces of paper (11 each), and were placed in a bowl. We asked the participants to each take a number so they can be assigned to the group the number represented. Their groups were assigned based on the random selection of the papers. Each student was given a two-digit code (01 to 22). The codes were used during the trial, instead of their names. 
The study had two phases. In each phase, one group was chosen as intervention, while the other group was the control group. Intervention and control groups were given the mouthwashes with and without T. polium, respectively. The codes of the students were written on mouthwash bottles and were given to the students, so that neither the students nor the laboratory personnel were aware of the type of mouthwash (double-blinded).

The volunteers were asked not to change their usual health care practices, but keep $15 \mathrm{~mL}$ of the mouthwash in their mouth for $30 \mathrm{~s}$ twice a day for two weeks. They, however, were requested to neither have food or beverages nor wash their mouthsfor almost $30 \mathrm{~min}$ [15]. After two weeks, they entered a 3-week washout phase (not using mouthwash). This exercise wasfor saliva's $S$. mutans value to return to initial levels [16]. In this phase, opposite to the first phase, placebo and T. polium mouthwashes were given to the first and second groups. Then, they were asked not to change their usual health care habits again, but keep $15 \mathrm{~mL}$ of the mouthwash in their mouth for $30 \mathrm{~s}$ twice a day for two weeks.

\section{Mouthwash preparation}

The extract of T. polium was prepared at the Faculty of Pharmacy, Kerman University of Medical Sciences.T. polium was collected from the mountainous area around Kerman, the capital city of Kerman province in the South East of Iran, in June. Plant flowers were cleaned, then washed with cold water and deionized water (Zolal Teb Shimi, Tehran, Iran), and were dried in a place away from direct sunlight. The dried samples were grounded with an electric mill (Moulinex 1043, Paris, France), and passed through a sieve with a mesh size of 32. Next, 250 $\mathrm{g}$ of the powder was soaked in 21 of water for $48 \mathrm{~h}$ and wasfiltered with a vacuum pump (Eyela A-35, Tokyo, Japan), a Buchner funnel (Isolab, Hannover, Germany), and a filter paper (Munktell, Bavaria, Germany). Obtained extracts were concentrated by vacuum distillation method at $52^{\circ}$ Celsius, using a rotary machine (Lab Tech EV 311-V, Rome, Italy). Eventually, concentrated extracts were dried in an oven (Memmert UF-55, Frankfurt, Germany) at $42^{\circ}$ Celsiusfor 3 days. Extraction yield was $10 \%$. Dried extract was kept in a freezer at $-22^{\circ}$ Celsius for further experimentation.

All components in the mouthwash, except for $T$. polium extract, were utilized to prepare the placebo. Distilled water (Zolal Teb Shimi, Tehran, Iran) was used instead of T. polium extracts to make the placebo.

Prepared mouthwashes were packed in matte plastic containers, and thenwere tagged with specific codes that were only known to the researchers, and were given to the volunteers. Each compound was prepared at the earliest time to its consumption to ensure the highest drug stability and the highest amount of active ingredients. After extract preparation, $0.2 \%$ concentration of mouthwash was chosen for further experiment due to its adequate taste. The mouthwash ingredients were as below: 1 Liter deionized water, $2 \mathrm{~g}$ of $T$. polium extracts, $1 \mathrm{~g}$ of artificial sweetener powder of $0.1 \%$ aspartame (Merck, Darmstadt, Germany), and $5 \mathrm{~g}$ powder of $0.5 \%$ coffee flavor (Nestle, Netherland, Holland).

\section{Saliva sampling}

To sample the volunteers' saliva, they were asked not take food or beverage for almost one hour prior to sampling. Sampling was done every day at 10 AM while $2 \mathrm{ml}$ of their unprovoked saliva was collected in a sterile container (spitting method) [17]. Unprovoked saliva sample of all individuals was taken at the beginning of the study, before using the mouthwash. The second test was conducted at the last day of the first phase of experiment using a spitting method. Participants were asked to take a minute's saliva in their mouth, and then pour in a sterile falcon tub.The third and fourth tests were done before and after the second phase. During the experiment, the volunteers were asked not to change their daily health care practices and brush their teeth using Crest toothpaste and Oral B toothbrushes.

\section{Colony count}

To determine the number of Streptococcus mutans colonies, samples were sent to the Laboratory of Microbiology, University of Rafsanjan, Iran. One day before saliva sampling, the culture medium was prepared. The TYCSB (Tryptone-Yeast-Cysteine-Sucrose-Bacitracin) medium of $S$. mutans was prepared in accordance with the standard protocol [18]. Standard 0.9\% NaCl (Zolal Teb Shimi, Tehran, Iran) was used to make a 1:1000 dilution of the samples, and then they were transferred to the plates containing $20 \mathrm{ml}$ agar TYCSB using a $0.01 \mathrm{ml}$ standard loop (Lab Tron, Tehran, Iran) [19]. The plates were placed in a $\mathrm{CO}_{2}$ incubator (Gallenkamp, Munich, Germany) at $37^{\circ}$ Celsius for $48 \mathrm{~h}$.

Accordingly, Gram's method was used to distinguish between gram negative and positive bacteria. Grampositive colonies (cocci) were selected to perform the catalase test. Next, catalase-negative cocci were incubated under biochemical tests for $48 \mathrm{~h}$ at $37^{\circ} \mathrm{Celsius}$. Based on previous recommendations [20, 21], colonies of positive mannitol, positive vogues-proskauer (VP), negative arginine, positive dextran, negative urease, and positive bileesculin were the target colonies. Eventually, Streptococcus mutans' colonies were calculated and were multiplied by dilution ratio to determine the number of colonies per one milliliter of each participant's saliva $(\mathrm{CFU} / \mathrm{mL})$. 


\section{Statistical analysis}

Data was analyzed by SPSS software (Version 18.0). Quantitative data was reported via the Mean value and Standard Deviation (numbers and percentages). Paired ttest was used to determine the effect of each mouthwash on the Streptococcus mutans's colonies. Moreover, an independent two-sample t-test was used to compare the Mean of Streptococcus mutans's colonies after mouthwash consumption in each phase of the experiment. Besides, crossover analysis was used to compare the mean of Streptococcus mutans's colonies after using T. polium and placebo mouthwashes during the study. As a final point, a standard $\mathrm{AB} / \mathrm{BA}$ crossover model was used to find the results of treatment and the carryover effect on the residual biological effects after using the mouthwash until the final phase [22]. The significant level was 0.05 in this experiment.

\section{Ethical considerations}

Ethics Committee of the Rafsanjan University of Medical Sciences approved the research's ethics. Approval number is $937 / 9 / 31$ with IRCT code number of IRCT2013121815842N1. Participants were asked to sign a written informed consent.

\section{Consolidated standards of reporting trials (CONSORT) flow diagram}

CONSORT flow diagram is seen in Fig. 2.

\section{Results}

Twenty-two dental students ( 11 male and 11 female students) participated in this research. The average age of participants was 23 (21 to 26 years old). The age difference between the two groups was not significant. The first group was the participants who used $T$. polium

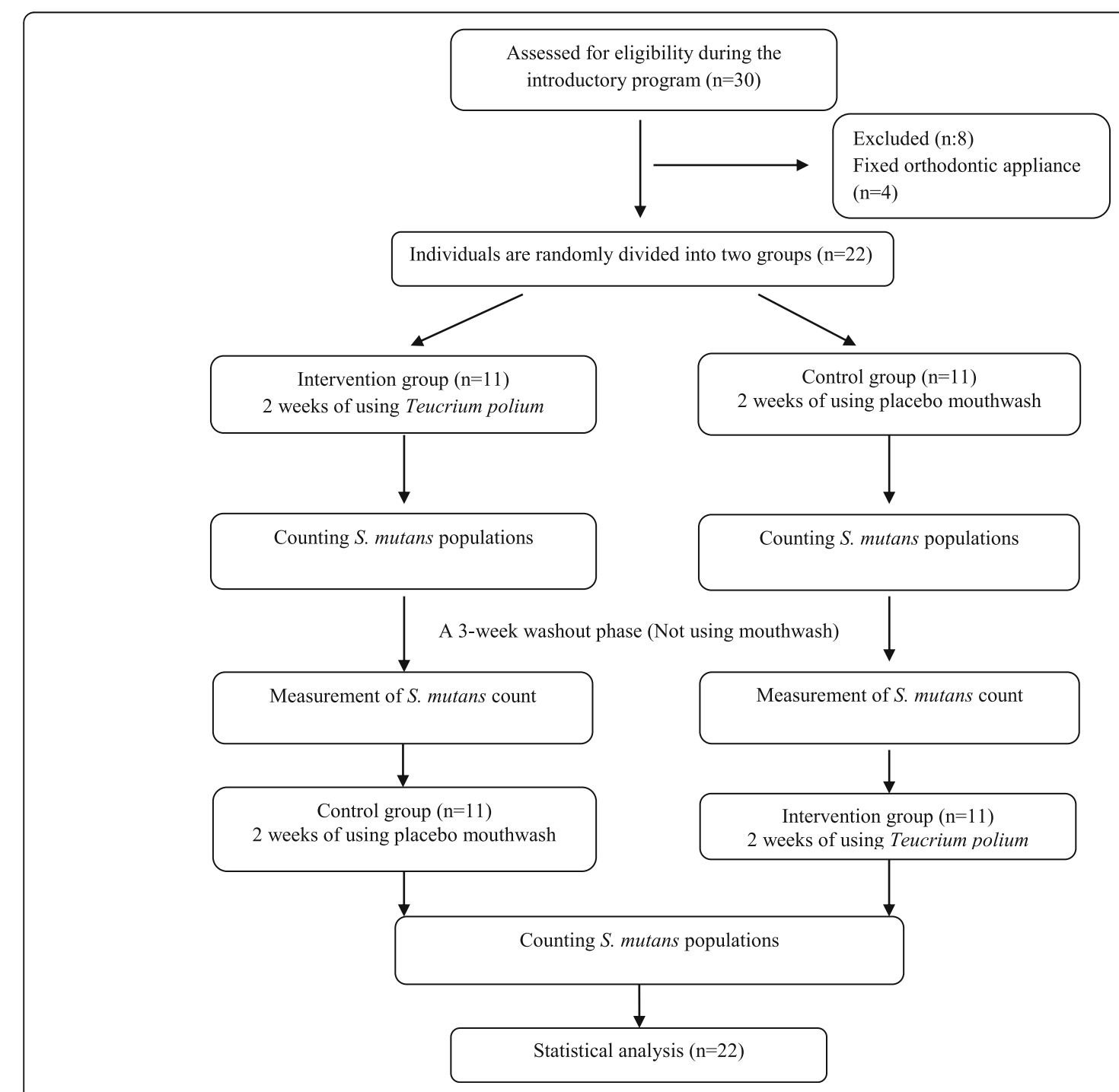

Fig. 2 CONSORT flow diagram 
mouthwash in the first phase, and then used the placebo mouthwash during the second phase. On the other hand, the second group used the T. polium and placebo mouthwash conversely. The first phase lasted for two weeks, and it was followed by a three-week washout period. The second phase commenced after the washout period and lasted for two weeks. The results showed that there was no statistical difference between the numbers of Streptococcus mutans's colonies per one milliliter of saliva in the groups before using the mouthwashes (Table 1).

In the first phase, $T$. polium mouthwash significantly pulled down the number of $S$. mutans' colonies $(P<$ $0.001)$. Nonetheless, placebo mouthwash did not significantly decrease the number of $S$. mutans' colonies $(P=$ 0.340 ). Moreover, the change in mean (decrease) in $S$. mutans' colonies was significantly higher in T. polium mouthwash than placebo mouthwash $(\mathrm{P}<0.001)$ (Fig. 3, Table 2).

At the second phase, after three weeks of washout period (without using the mouthwashes), the first group used the placebo mouthwash, while the second group used the $T$. polium mouthwash. Placebo mouthwash, again, did not significantly decrease the number of $S$. mutans' colonies $(P=0.279)$. The use of $T$. polium mouthwash resulted in a significant reduction in the number of $S$. mutans' colonies $(P<0.001)$. Additionally, the mean change (decrease) in the number of $S$. mutans' colonies in the $T$. polium group was significantly higher than the placebo group $(P=0.001)$ (Table 2).

Finally, the standard $\mathrm{AB} / \mathrm{BA}$ crossover model analysis was conducted to find the carryover effect. The difference between the change in $S$. mutans colonies before and after using mouthwashes in the first phase (Y1) and the second phase (Y2) were calculated. This difference was significant $(P<0.001)$. It showed that an effective treatment or carryover effect existed between the treatments. To find out where the effect came from (due to the treatment or carryover effect), the second part of this analysis was conducted. In this part the sum of $\mathrm{Y} 1$ and Y2 was analyzed, and showed no significant differences, which approves that there is no carryover effect. Comparison of T. polium and placebo mouthwashes using crossover analysis showed that T. polium mouthwash significantly reduced the number of $S$. mutans' colonies $(\mathrm{P}<0.001)$ (Additional file 2).

\section{Discussion}

Tooth decay is an epidemic problem in the world. While the chemical mouthwashes have their own side effects, including discolorations of tongue and tooth surfaces, alteration in taste perception, soft tissue irritations and burning sensation [23], herbal mouthwashes seem to be an appropriate substitute [24-26]. Results of this study proved that a mouthwash containing T. polium can effectively decrease $S$. mutans population in the mouth, and this effect can last for at least three weeks after using the mouthwash.

During the first phase of the current research, the participants noticed a tangible difference in the taste of the mouthwash containing $T$. polium, due to their treatment. It is worthy to mention this limitation was predicted before the study was conducted and several steps were designed to reduce its impacton the outcomes. Firstly, the participants voluntarily contributed to the study and the importance of following the study protocol was discussed with them. In addition, since the participants were selected from dental students (not from a general demographics), they were more likely to cooperate with the research team and understood the drawbacks. Secondly, the study was designed as an $\mathrm{AB} / \mathrm{BA}$ crossover study, and a standard AB/BA crossover statistical model was utilized to analyze the outcomes and test the possible carryover effects.

S. mutans is considered to be the most important and pathogenic decay microorganism and it plays a major role in the onset of caries [27]. In the present study, the effect of T. polium mouthwash on saliva's $S$. mutans was investigated. The design of the study in crossover model has been considered as its strong point, since its twostep design (two phases) increased its accuracy. The positive results of the two phases emphasize the efficacy of the antibacterial properties of the polei-gamander plant on S. mutans. In this cross-over study, two positive effects of T. polium mouthwash were observed: A reduction in the number of $S$. mutans colonies during the time when T. polium mouthwash was used and the continuous antimicrobial effect of the mouthwash in the

Table 1 Variables in both A and B groups before starting the study

\begin{tabular}{|c|c|c|c|c|}
\hline \multirow[t]{2}{*}{ Variables } & & & \multicolumn{2}{|l|}{ groups } \\
\hline & & & A & B \\
\hline \multirow[t]{2}{*}{ Gender } & Male & Count (percent) & $5(45.5 \%)$ & $6(54.5 \%)$ \\
\hline & Female & Count (percent) & $6(54.5 \%)$ & $5(45.5 \%)$ \\
\hline Age & \multicolumn{2}{|c|}{ Mean year } & $23.09( \pm 1.64)$ & $23.18( \pm 1.78)$ \\
\hline _Salivas'S. mutans_population before starting the trial & \multicolumn{2}{|c|}{ Mean $\left({ }^{*} 10^{6} \mathrm{CFU} / \mathrm{mL}\right)$} & $7.24( \pm 1.69)$ & $7.86( \pm 1.28)$ \\
\hline
\end{tabular}




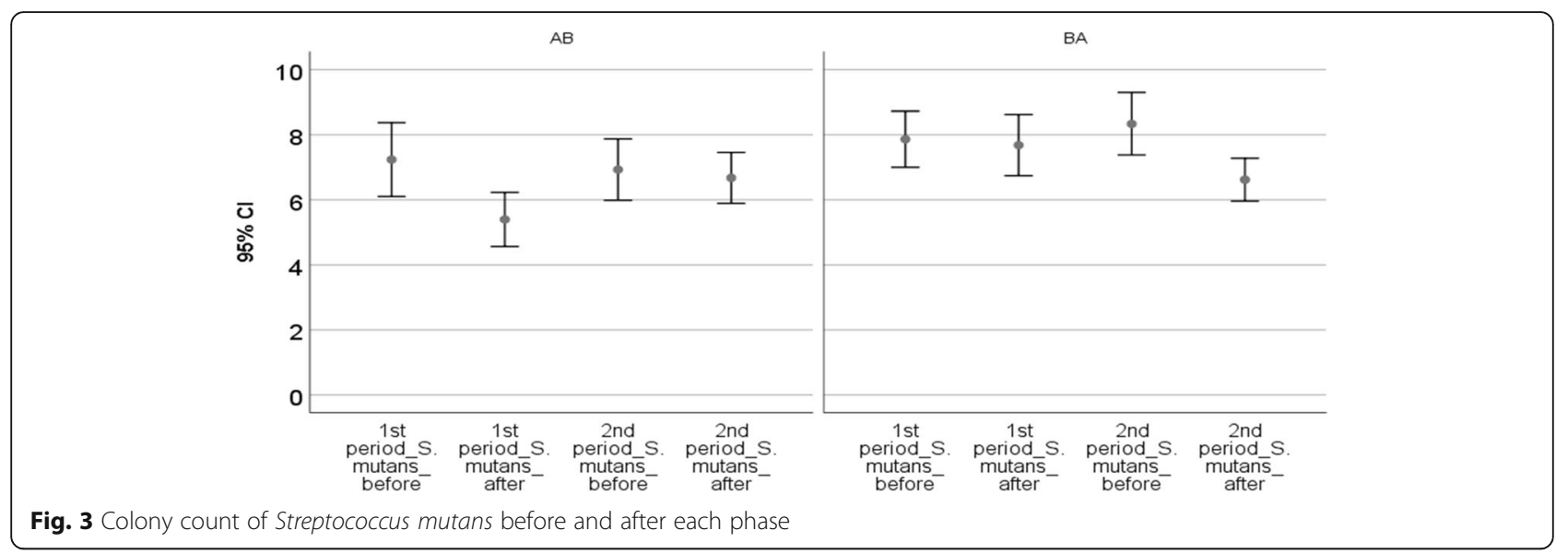

washout period. In the Intervention group, there was a significant reduction in $S$. mutans in both phases, while in the control group, only a slight decrease inthe microbial colonieswas obtained due to the regular use of mouthwash. The counting of microbial colonies of saliva before and after each phase depicts the capability of the contributions this research has made.

In studies that investigate the antimicrobial effects of mouthwashes, the duration of the washout period is usually two to three weeks $[26,28]$. In the current study, the washout period was three weeks after which the $S$. mutans value did not return to the initial level. This indicates a potent antibacterial effect of the $T$. polium mouthwash. Consequently, at the end of the second phase, when both groups had used T. polium mouthwash, similar results of a reduction in the microbial colony were observed. Using standard $\mathrm{AB} / \mathrm{BA}$ crossover model analysis [22] indicated that there were no carryover effects.

Studies on antibacterial activity of herbal plants have shown different results. The findings of this research demonstrate that $T$. polium mouthwash, compared to the placebo mouthwash, can significantly reduce the rate of salivary S. mutans. Mehta et al (2013) showed that a commercial herbal mouthwash had similar effect on reducing the salivary $S$. mutans as chlorhexidine $(P=$ 0.639) [26]. Shah et al.(2018) had a randomized controlled pilot study on comparing an herbal mouthwash and a mouthwash containing $0.2 \%$ chlorhexidine on reducing salivary S. mutans. Their herbal mouthwash containing twelve herbal plants was significantly more effective than the $0.2 \%$ chlorhexidine mouthwash in reducing oral $S$. mutans population $(P<0.001)$. They also illustrated that their herbal mouthwash had no side effects on oral or dental tissues [25]. Furthermore, a systematic review in 2018 indicated that herbal products exerted almost comparable antibacterial effect against $S$. mutans comparing with chlorhexidine [29]. Haffajee et al. [30] found that herbal mouthwashescan be effective in preventing the growth of oral microbes and can be useful in controlling dental plaques and inflammation of the gum. The range of effectiveness of antibacterial

Table 2 Colony count of Streptococcus mutans before and after of each phase, and significances of effectiveness of using mouthwashes intergroups and intragroups

\begin{tabular}{|c|c|c|c|c|}
\hline & & Group 1 & Group 2 & $p$-value * \\
\hline Treatment in the first phase & & Treatment A & Treatment B & \\
\hline 1st period_S.mutans_before & Mean & 7.24( \pm 1.69$)$ & $7.86( \pm 1.28)$ & \\
\hline 1st period_S.mutans_after & Mean & $5.39( \pm 1.24)$ & $7.68( \pm 1.40)$ & \\
\hline Difference of S.mutans before and after the use of mouthwash in first phase & Mean & $1.85( \pm 0.87)$ & $0.18( \pm 0.60)$ & $<0.001$ \\
\hline $\mathrm{p}$-value in treatment & & $<0.001$ & $=0.340$ & \\
\hline Treatment in the second phase & & Treatment B & Treatment A & \\
\hline 2nd period_S.mutans_before & Mean & $6.93( \pm 1.41)$ & $8.34( \pm 1.42)$ & \\
\hline 2nd period_S.mutans_after & Mean & $6.67( \pm 1.17)$ & $6.62( \pm 0.98)$ & \\
\hline Difference of S.mutans before and after the use of mouthwash in second phase & Mean & $0.25( \pm 0.74)$ & $1.72( \pm 1.09)$ & $=0.001$ \\
\hline$p$-value in treatment & & $=0.279$ & $<0.001$ & \\
\hline
\end{tabular}

* $p$-value in decreasing the colonies between two groups at the end of each period 
effect for polei-gamander plant has been widely reported in different studies. Mosadegh et al. [31] reported a weak antibacterial effect of ethanolic extract of poleigamander plant on Staphylococcus, Micrococcus luteus, and Escherichia coli, while the antibacterial effect in our research was strong. The differences in such reports might be due to various types of bacteria, and different extraction methods.

Phenolic compounds which are present in T. polium herb could be the factor which is reducing the number of salivary $S$. mutans. Bravo showed that gram-positive and gram-negative bacteria are sensitive to the phenolic compounds, which are widely distributed substances in many plants [32]. Antimicrobial effects of these compounds depend on the number and the position of the phenol hydroxyl groups. It has been claimed that the toxicity effect of these compounds on the microorganisms is directly correlated with the numbers of hydroxyl groups [33]. Another antimicrobial component existing in T. polium herb is tannin compound. Antimicrobial effects of these compounds are due to both suppression of tenacity of the microbes and blockage of microbial enzymatic activity [34].

Our study exhibited a positive result, nonetheless, the effects of T. polium mouthwash has not been compared to chlorhexidine as a gold standard. It is highly suggested to investigate and to compare the effect of poleigamander plant's active ingredients on different bacterial strains with that of chlorhexidinein the upcoming researches.

\section{Conclusion}

The results of the current research indicate the aqueous extract of $T$. polium significantly reduces the colonization of $S$. mutans in human saliva. This decline was visible even after three weeks of washout period. Overall, it can be concluded the use of $T$. polium mouthwash, on a periodic basis, can reduce the risk of tooth decays. These findings can also contribute to the ingredients of other oral hygiene materials like toothpastes or chewing gums.

\section{Supplementary information}

Supplementary information accompanies this paper at https://doi.org/10. 1186/s12903-020-01116-4.

Additional file 1

Additional file 2. Standard AB/BA crossover model analysis.

\section{Abbreviations}

S. mutans: Streptococcus mutans; T. polium: Teucrium polium; IRCT: Iranian Registry of Clinical Trials; TYCSB: Tryptone-Yeast-Cysteine-Sucrose-Bacitracin; VP: vogues-proskauer; CFU: colony forming unit; CONSORT: Consolidated Standards of Reporting Trials

\section{Acknowledgments}

The authors wish to thank Rafsanjan University of Medical Sciences for their all supports and to be grateful for students' participating in the study.

\section{Authors' contributions}

SKT made contributions to the conceptual design of the work, and also drafted the work and revisedearly drafts. AJ made contributions to the conceptual design of the work, and also drafted the work and revised early drafts and submitted the manuscript. SMAM made contributions to supervise the microbial tests. SFN wrote the manuscript and revised early drafts. MF helped in the acquisition, analysis, and interpretation of data. MA made contributions to prepare the extract of Teucriumpolium and mouthwashes. All authors read and approved the final manuscript.

\section{Funding}

No funding was obtained for this study.

Availability of data and materials

Data of this study is attached as a Microsoft excel file.

\section{Ethics approval and consent to participate}

The present study was approved by the Ethics Committee of Rafsanjan University of Medical Sciences with the approval number of 937/9/31 and Iranian Registry of Clinical Trials (IRCT) code No. IRCT2013121815842N1. All the participants signed a written informed consent form. Attendance in this study was not compulsory and the participants did not receive any course credits for attending.

\section{Consent for publication}

Not applicable.

\section{Competing interests}

The authors declare that there are not any competing interests.

\section{Author details}

${ }^{1}$ Department of Pediatric Dentistry, School of Dentistry, Alborz University of Medical Sciences, Alborz, Iran. ${ }^{2}$ Research Center for Caries Prevention, Dental Research Institute, Department of Community Oral Health, School of Dentistry, Tehran University of Medical Sciences, Tehran, Iran. ${ }^{3}$ Department of Pediatric Dentistry, School of Dentistry, Al Hussain University, Karbala, Iraq. ${ }^{4}$ Department of Microbiology, Qazvin University of Medical Sciences, Qazvin, Iran. ${ }^{5}$ Department of Community Medicine, School of Medicine, Alborz University of Medical Sciences, Alborz, Iran. ${ }^{6}$ Department of Pharmaceutics, Faculty of Pharmacy, Kerman University of Medical Sciences, Kerman, Iran.

Received: 28 January 2020 Accepted: 19 April 2020

Published online: 01 May 2020

\section{References}

1. Farrell JJ, Zhang L, Zhou H, Chia D, Elashoff D, Akin D, et al. Variations of oral microbiota are associated with pancreatic diseases including pancreatic cancer. Gut. 2012:61(4):582-8.

2. Weidlich P, Cimões R, Pannuti CM, Oppermann RV. Association between periodontal diseases and systemic diseases. Brazilian Oral Res. 2008:22:3243.

3. Meyer K, Geurtsen W, Günay H. An early oral health care program starting during pregnancy. Clin Investig. 2010;14(3):257-64.

4. Palombo EA. Traditional medicinal plant extracts and natural products with activity against oral bacteria: potential application in the prevention and treatment of oral diseases. Evid Based Complement Alternat Med. 2011; 2011:1-15.

5. Vlachojannis $\mathrm{C}$, Winsauer $\mathrm{H}$, Chrubasik S. Effectiveness and safety of a mouthwash containing essential oil ingredients. Phytother Res. 2013;27(5): 685-91.

6. Emmadi P, Ambalavanan N, Ramakrishnan T, Vijayalakshmi R. Effect of three commercial mouth rinses on cultured human gingival fibroblast: and in vitro study. Indian J Dent Res. 2008:19(1):29.

7. James P, Worthington HV, Parnell C, Harding M, Lamont T, Cheung A, Whelton $\mathrm{H}$, Riley $\mathrm{P}$. Chlorhexidine mouthrinse as an adjunctive treatment for gingival health. Cochrane Database Syst Rev. 2017;3:25-6. 
8. Bahramikia S, Yazdanparast R. Phytochemistry and medicinal properties ofTeucrium polium L. (Lamiaceae). Phytother. Res. 2012;26:1581-93.

9. Ali-Shtayeh MS, Yaniv Z, Mahajna J. Ethnobotanical survey in the Palestinian area: a classification of the healing potential of medicinal plants. J Ethnopharmacol. 2000;73(1-2):221-32.

10. Al-Khalil S. A survey of plants used in Jordanian traditional medicine. Int J Pharmacogn. 1995;33(4):317-23.

11. Alizadeh AM, Sohanaki H, Khaniki M, Mohaghgheghi MA, Ghmami G, Mosavi M. The effect of Teucrium Polium Hney on the wound healing and tensile strength in rat. Iran J Basic Med Sci. 2011;14(6):499.

12. Alzweiri M, Al Sarhan A, Mansi K, Hudaib M, Aburjai T. Ethnopharmacological survey of medicinal herbs in Jordan, the northern Badia region. J Ethnopharmacol. 2011;137(1):27-35.

13. Mahmoudi R, Kazeminia M, Ghajarbeygi P, Pakbin B. An introductory review on increasing the survival of probiotic bacteria in dairy products using essential oil. J Dent Oral Health. 2017;3(4):069.

14. Khosravanifard B, Ghasemi M, Rastegarian H, Sajadi H, Emami H, Amani M. Effect of three different mouthrinses on mutans Streptococci accumulation around orthodontic brackets. J Res Dent Sci. 2008;5(1):38-46 [Abstract in English].

15. Karami M, Mazaheri R, Mesripour M. Comparing the effectiveness of two fluoride mouth rinses on Streptococcus mutans. J Mash Dent Sch. 2011; 35(2):115-22 [Abstract in English].

16. Vieira AR, Deeley KB, Callahan NF, Noel JB, Anjomshoaa I, Carricato WM, et al. Detection of Streptococcus mutans genomic DNA in human DNA samples extracted from saliva and blood. ISRN Dent. 2011;2011:1-6.

17. Emamieh S, Khaterizadeh Y, Goudarzi H, Ghasemi A, BaghbanAA TH. The effect of two types chewing gum containing casein phosphopeptideamorphous calcium phosphate and xylitol on salivary Streptococcus mutans. J Conserv Dent. 2015;18(3):192-5.

18. Luce E. Koneman's color atlas and textbook of diagnostic microbiology. Plast Reconstr Surg. 2010;125(1):414-5.

19. Srinagesh J, Krishnappa P, Somanna SN. Antibacterial efficacy of triphala against oral streptococci: an in vivo study. Indian J Dent Res. 2012;23(5):696.

20. Hamada S, Slade HD. Biology, immunology, and cariogenicity of Streptococcus mutans. Microbiol Rev. 1980;44(2):331.

21. Whiley RA, Hardie JM. Streptococcus vestibularis sp. nov. from the human oral cavity. Int J Syst Evol Microbiol. 1988;38(4):335-9.

22. Reed JF. Analysis of two-treatment, two-period crossover trials in emergency medicine. Ann Emerg Med. 2004;43(1):54-8.

23. Gürgan CA, Zaim E, Bakirsoy I, Soykan E. Short-term side effects of $0.2 \%$ alcohol-free chlorhexidine mouthrinse used as an adjunct to non-surgical periodontal treatment: a double-blind clinical study. J Periodontol. 2006; 77(3):370-84.

24. Jassoma E, Baeesa $L$, Sabbagh $H$. The antiplaque/anticariogenic efficacy of Salvadora persica (Miswak) mouthrinse in comparison to that of chlorhexidine: a systematic review and meta-analysis. BMC Oral Health. 2019:19(1):64.

25. Shah S, Bargale S, Dave BH, Deshpande A, Kariya PB, Karri A. Comparison of antimicrobial efficacy of (between) $0.2 \%$ chlorhexidine and herbal mouthwash on salivary Streptococcus mutans: a randomized controlled pilot study. Contemp Clin Dent. 2018;9(3):440-5.

26. Mehta S, Pesapathy S, Joseph M, Tiwari PK, Chawla S. Comparative evaluation of a herbal mouthwash (Freshol) with chlorhexidine on plaque accumulation, gingival inflammation, and salivary Streptococcus mutans growth. J Int Soc Prev Community Dent. 2013;3(1):25-8.

27. Johansson I, Witkowska E, Kaveh B, Lif Holgerson P, Tanner ACR. The microbiome in populations with a low and high prevalence of caries. J Dent Res. 2016:95(1):80-6.

28. Moeiny P, Jamei N, Mohamadi M, SHafizadeh N, Valaei N, Rahbar M, KHosravi K. Effect of a probiotic yogurt produced in Iran on the salivary counts of Streptococcus mutans. Res Dent Sci. 2013;10(2):73-82.

29. Jacob B, Nivedhitha MS. Comparative assessment of the antibacterial efficacy of natural products and Chlorhexidine mouthwash against Streptococcus Mutans: a systematic review. J Clin Diagn Res. 2018;12(12):17.

30. Haffajee AD, Yaskell T, Socransky SS. Antimicrobial effectiveness of an herbal mouthrinse compared with an essential oil and a chlorhexidine mouthrinse. J Am Dent Assoc. 2008;139(5):606-11.
31. Mosadegh M, Dehmoubed SA, Nasiri P, Esmaeili S, Naghibi F. The study of phytochemical, antifungal and antibacterial effects of Teucrium polium and Cichourium intybus. Sci J Kurdist Univ Med Sci. 2002;7(1):1-6.

32. Bravo L. Polyphenols: chemistry, dietary sources, metabolism, and nutritional significance. Nutr Rev. 1998;56(11):317-33.

33. Othman MB, Salah-Fatnassi KBH, Ncibi S, Eliassi A, Zourgui L. antimicrobial activity of essential oil and aquios and ethanol extracts of Teucrium polium L. subsp. Gabesianum (LH) from Tunesia. Physciol Mol Biol Plants. 2017;23(3): 723-9.

34. Seabra RM, Andrade PB, Valentão P, Fernandes E, Carvalho F, Bastos ML. In: Fingerman M, Nagabhushanam R, editors. In Biomaterials from Aquatic and Terrestrial organisms. Enfield: Science Publishers; 2006. p. 115-174. 5.

\section{Publisher's Note}

Springer Nature remains neutral with regard to jurisdictional claims in published maps and institutional affiliations.
Ready to submit your research? Choose BMC and benefit from:

- fast, convenient online submission

- thorough peer review by experienced researchers in your field

- rapid publication on acceptance

- support for research data, including large and complex data types

- gold Open Access which fosters wider collaboration and increased citations

- maximum visibility for your research: over $100 \mathrm{M}$ website views per year

At BMC, research is always in progress.

Learn more biomedcentral.com/submissions 